\title{
Validation List no. 128 \\ List of new names and new combinations previously effectively, but not validly, published
}

\author{
Correspondence \\ Jean Euzéby \\ email address can be found at \\ www.bacterio.net
}

\begin{abstract}
The purpose of this announcement is to effect the valid publication of the following effectively published new names and new combinations under the procedure described in the Bacteriological Code (1990 Revision). Authors and other individuals wishing to have new names and/or combinations included in future lists should send three copies of the pertinent reprint or photocopies thereof, or an electronic copy of the published paper, to the IJSEM Editorial Office for confirmation that all of the other requirements for valid publication have been met. It is also a requirement of IJSEM and the ICSP that authors of new species, new subspecies and new combinations provide evidence that types are deposited in two recognized culture collections in two different countries. It should be noted that the date of valid publication of these new names and combinations is the date of publication of this list, not the date of the original publication of the names and combinations. The authors of the new names and combinations are as given below, and these authors' names will be included in the author index of the present issue. Inclusion of a name on these lists validates the publication of the name and thereby makes it available in bacteriological nomenclature. The inclusion of a name on this list is not to be construed as taxonomic acceptance of the taxon to which the name is applied. Indeed, some of these names may, in time, be shown to be synonyms, or the organisms may be transferred to another genus, thus necessitating the creation of a new combination.
\end{abstract}

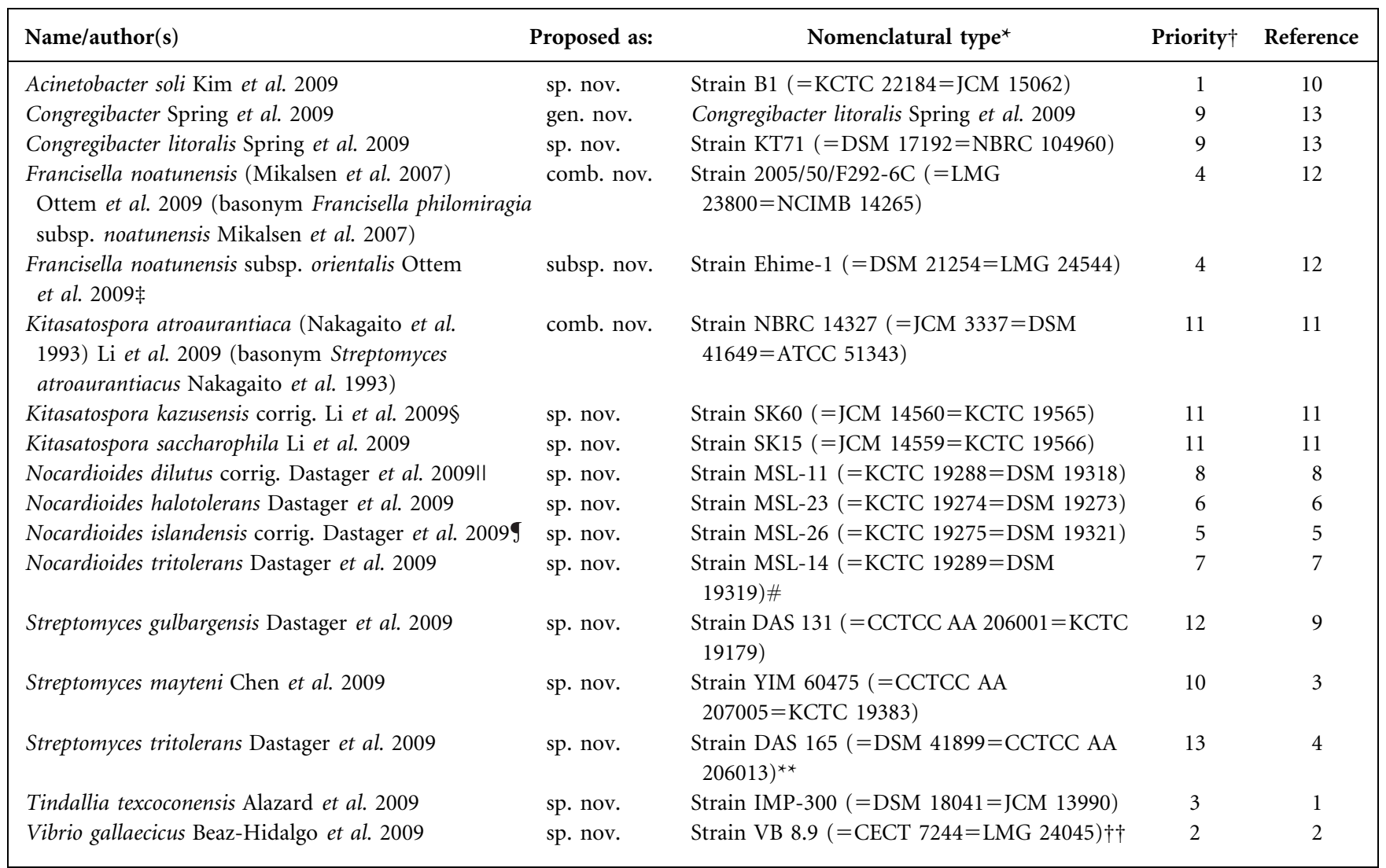


cont.

For references to Validation Lists 1-71, see Int J Syst Bacteriol 49 (1999) 1325. Lists 72-127 were published in Int J Syst Evol Microbiol 50 (2000) 3, 423, 949, 1415, 1699, 1953; and 51 (2001) 1, 263, 793, 1229, 1619, 1945; and 52 (2002) 3, 685, 1075, 1437, 1915; and 53 (2003) 1, 373, 627, 935, 1219, 1701; and 54 (2004) 1, 307, 631, 1005, 1425, 1909; and 55 (2005) 1, 547, 983, 1395, 1743, 2235; and 56 (2006) 1, 499, 925, 1459, 2025, 2507; and 57 (2007) 1, 433, 893, 1371, 1933, 2449; and 58 (2008) 1, 529, 1057, 1511, 1993, 2471; and 59 (2009) 1, 451, 923.

${ }^{\star}$ Abbreviations of culture collections cited in this list can be found at http://ijs.sgmjournals.org/misc/collections.dtl

$\dagger$ Priority number assigned according to the date the documentation and request for validation are received.

¥According to Rule 40d (formerly Rule 46) of the Bacteriological Code (1990 Revision), the valid publication of Francisella noatunensis subsp. orientalis Ottem et al. 2009 automatically creates another subspecies, Francisella noatunensis subsp. noatunensis (Mikalsen et al. 2007) Ottem et al. 2009.

§The original spelling of the specific epithet, kazusanensis (sic), has been corrected on validation according to Rule 61. The etymology of the specific epithet is the following: ka.zu.sen'sis. N.L. fem. adj. kazusensis from or pertaining to Kazusa, the city in Japan where the organism was isolated. IIThe specific epithet dilutes ( sic) has been corrected on validation according to Rule 61. The etymology of the specific epithet is the following: di.lu'tus. L. masc. adj. dilutus weak, diluted, intended to mean that the organism is able to grow in 100 times diluted R2A medium.

The specific epithet islandiensis ( sic) has been corrected on validation according to Rule 61. The etymology of the specific epithet is the following: is.lan.den'sis. N.L. masc. adj. islandensis from or pertaining to Bigeum Island in Korea, from where the type strain was isolated.

\#In the effective publication, the strain DSM 19319 is erroneously cited as DSM 19320.

${ }^{*}$ The accession numbers DSM 41899 and CCTCC AA 206013 have been provided on validation; i.e. they are not cited in the protologue of the effective publication.

$\dagger \dagger$ In the protologue of the effective publication, the type strain CECT 7244 is erroneously cited as CECT 7224 .

\section{References}

1. Alazard, D., Badillo, C., Fardeau, M.-L., Cayol, J.-L., Thomas, P., Roldan, T., Tholozan, J.-L. \& Ollivier, B. (2007). Tindallia texcoconensis sp. nov., a new haloalkaliphilic bacterium isolated from lake Texcoco, Mexico. Extremophiles 11, 33-39.

2. Beaz-Hidalgo, R., Doce, A., Pascual, J., Toranzo, A. E. \& Romalde, J. L. (2009). Vibrio gallaecicus sp. nov. isolated from cultured clams in north-western Spain. Syst Appl Microbiol 32, 111-117.

3. Chen, H.-H., Qin, S., Lee, J.-C., Kim, C.-J., Xu, L.-H. \& Li, W.-J. (2009). Streptomyces mayteni sp. nov., a novel actinomycete isolated from a Chinese medicinal plant. Antonie Van Leeuwenhoek 95, 47-53.

4. Dastager, S. G., Agasar, D., Kim, C.-J., Li, W.-J., Lee, J.-C., Park, D.J., Xu, L.-H., Tian, X.-P. \& Jiang, C.-L. (2007). Streptomyces tritolerans sp. nov., a novel actinomycete isolated from soil in Karnataka, India. Antonie Van Leeuwenhoek 92, 391-397.

5. Dastager, S. G., Lee, J.-C., Ju, Y.-J., Park, D.-J. \& Kim, C.-J. (2008). Nocardioides islandiensis sp. nov., isolated from soil in Bigeum Island Korea. Antonie Van Leeuwenhoek 93, 401-406.

6. Dastager, S. G., Lee, J.-C., Ju, Y.-J., Park, D.-J. \& Kim, C.-J. (2008). Nocardioides halotolerans sp. nov., isolated from soil on Bigeum Island, Korea. Syst Appl Microbiol 31, 24-29.

7. Dastager, S. G., Lee, J.-C., Ju, Y.-J., Park, D.-J. \& Kim, C.-J. (2008). Nocardioides tritolerans sp. nov., isolated from soil in Bigeum Island, Korea. J Microbiol Biotechnol 18, 1203-1206.
8. Dastager, S. G., Lee, J.-C., Ju, Y.-J., Park, D.-J. \& Kim, C.-J. (2008), Nocardioides dilutes sp. nov. isolated from soil in Bigeum Island, Korea. Curr Microbiol 56, 569-573.

9. Dastager, S. G., Li, W.-J., Agasar, D., Sulochana, M. B., Tang, S.-K., Tian, X.-P. \& Zhi, X.-Y. (2007). Streptomyces gulbargensis sp. nov., isolated from soil in Karnataka, India. Antonie Van Leeuwenhoek 91, 99-104.

10. Kim, D., Baik, K. S., Kim, M. S., Park, S. C., Kim, S. S., Rhee, M. S., Kwak, Y. S. \& Seong, C. N. (2008). Acinetobacter soli sp. nov., isolated from forest soil. J Microbiol 46, 396-401.

11. Li, B., Furihata, K., Kudo, T. \& Yokota, A. (2009). Kitasatospora saccharophila sp. nov. and Kitasatospora kazusanensis sp. nov., isolated from soil and transfer of Streptomyces atroaurantiacus to the genus Kitasatospora as Kitasatospora atroaurantiaca comb. nov. J Gen Appl Microbiol 55, 19-26.

12. Ottem, K. F., Nylund, A., Karlsbakk, E., Friis-Møller, A. \& Kamaishi, T. (2009). Elevation of Francisella philomiragia subsp. noatunensis Mikalsen et al. (2007) to Francisella noatunensis comb. nov. [syn. Francisella piscicida Ottem et al. (2008) syn. nov.] and characterization of Francisella noatunensis subsp. orientalis subsp. nov., two important fish pathogens. J Appl Microbiol 106, 1231-1243.

13. Spring, S., Lünsdorf, H., Fuchs, B. M. \& Tindall, B. J. (2009). The photosynthetic apparatus and its regulation in the aerobic gammaproteobacterium Congregibacter litoralis gen. nov., sp. nov. PLoS One 4, e4866. doi:10.1371/journal.pone.0004866 